\title{
GEOLOGIA, ESTRATIGRAFIA E DEPÓSITOS MINERAIS DO PROJETO VILA NOVA, ESCUDO DAS GUIANAS, AMAPÁ, BRASIL
}

\author{
CARLOS ALBERTO SPIER* \& CÉSAR FONSECA FERREIRA FILHO**
}

\begin{abstract}
GEOLOGY, STRATIGRAPHY AND MINERAL DEPOSITS OF THE VILA NOVA PROJECT, GUYANA SHIELD, AMAPÁ, BRAZIL The Vila Nova Project covers an área of $170 \mathrm{~km}$ located at the center-southeast of the Amapa State, Brazil. The Project area comprises granite-gneiss terrains, mafic-ultramafic rocks, volcanic-sedimentary association and intrusive granitic and basic intrusive. Upper amphibolite facies metamorphism affected the mafic-ultramafic rocks as well as the volcanic-sedimentary association. Several ore bodies of chromium, gold and iron together with occurrences of diamond and tantalite indicate the anomalous concentration of mineral deposits in the region. The maficultramafic rocks, named Mafic-Ultramafic Bacuri Complex, are intrusive in the granite-gneiss terrains and older than the volcanicsedimentary association. The Bacuri Complex hosts 11 stratiform deposits with proven chromitite reserves of $9 \mathrm{Mt}$, indicating an extensive mantelic magmatism. The volcanic-sedimentary association is correlated to the Vila Nova Group and consists of fine- and coarse-grained clastic metasediments and chemical metasediments with basic metavolcanics interlayered. This association hosts deposits of gold and iron and corresponds to a Paleoproterozoic greenstone belt broadly comparable to the Guyana Shield greenstone belts.

Keywords: Vila Nova, Bacuri Complex, chromite, gold, iron, mafic-ultramafic, greenstone belt.

RESUMO O Projeto Vila Nova compreende uma área de $170 \mathrm{~km}^{2}$ localizada no centro- sudeste do Estado do Amapá, Brasil, onde ocorrem terrenos granítico-gnáissicos, rochas máfico-ultramáficas, associação vulcano-sedimentar e rochas graníticas e básicas intrusivas. Metamorfismo de fácies anfibolito superior afeta tanto as rochas máfico-ultramáficas quanto a associação vulcano-sedimentar. Minas de cromo e ouro, depósitos de ferro e ouro, além de ocorrências de tantalita e diamante definem a concentração anômala de depósitos minerais na região. As rochas máficoultramáficas, denominadas de Complexo Máfico-Ultramáfico Bacuri, são intrusivas nos terrenos granítico-gnáissicos e mais antigas do que a associacão vulcano-sedimentar. O Complexo Bacuri hospeda 11 depósitos de cromita estratiforme com reservas superiores a 9 Mt de cromitito, indicando a existência de importante magmatismo mantélico. A associação vulcano-sedimentar é correlacionada ao Grupo Vila Nova e consiste de rochas metassedimentares elásticas grossas a finas e rochas metassedimentares químicas com metavulcânicas interçaladas. Esta associação hospeda depósitos de ouro e ferro e corresponderia à uma sequência do tipo greenstone belt, de idade Paleoproterozóica, genericamente comparável aos greenstone belts do noroeste do Escudo das Guianas.
\end{abstract}

Palavras-chave: Vila Nova, Complexo Bacuri, cromita, ouro, ferro, máfico-ultramáfico, sequência vulcano-sedimentar.

INTRODUÇÃ O O Projeto Vila Nova (VNO) compreende uma área de $170 \mathrm{~km}^{2}$ localizada no centro-sudeste do Estado do Amapá, Norte do Brasil, onde o Grupo CAEMI desenvolveu pesquisa mineral nos últimos 15 anos. Muitos depósitos minerais de diferentes tipos foram descobertos e explorados na área do projeto. Estes incluem diferentes tipos de depósitos de ouro, vários corpos de cromitito estratiforme e depósitos de minério de ferro, além de ocorrências e garimpes de tantalita e diamante, todos localizados $90 \mathrm{~km}$ a sudeste dos depósitos de manganês de Serra do Navio. A recente descoberta do depósito de ouro da Serra da Canga, localizado a $10 \mathrm{~km}$ a leste da Serra do Navio, com reservas estimadas superiores a $60 \mathrm{t}$ de ouro, marca a concentracão anómala de depósitos minerais nesta região, onde muitas companhias de mineração estão desenvolvendo pesquisas. $\mathrm{O}$ potencial geológico para descobertas adicionais é grande e a região pode tornar-se uma nova Província Mineral no Brasil.

A exploração e mineração no Projeto VNO gerou uma quantidade extensiva de dados geológicos, geoquímicos e geofísicos, incluindo mais de 100.000 metros de testemunhos de sondagem. Estes dados nunca foram publicados, a despeito do longo tempo de atividade mineral na área. Este trabalho descreve a geologia, estratigrafía e depósitos minerais do Projeto VNO, buscando situá-los no contexto da geologia regional do Estado do Amapá e do Escudo das Guianas, criando uma base para os estudos petrológicos-geocronológicos-metalogenéticos ora em desenvolvimento na área.

GEOLOGIA REGIONAL Segundo Tassinari (1997) o Cráton Amazônico, do qual o Escudo das Guianas forma a parte Norte, compreende um domínio estável antigo, conhecido como Província Amazônica Central, rodeado por faixas móveis de idade Mesoproterozóica a Paleoproterozóica. O Estado do Amapá situa-se no âmbito da Faixa Móvel Maroni-Itacaiunas (Fig. 1), formada por complexos granito-gnáissicos com um núcleo granulítico e faixas vulcano-sedimentares metamorfisadas na fácies xisto verde até anfibolito. Remanescentes de rochas do embasamento Arqueano foram identificadas, a maioria das quais formada por rochas granulíticas parcialmente retrabalhadas durante o Paleoproterozóico (Tassinari 1997).

A evolucão do conhecimento geológico no Estado do Amapá deuse a partir da descoberta dos depósitos de manganês de Serra do Navio, na década de 40 e com os programas de mapeamento regional executados pelo DNPM, CPRM e Projeto RADAM na década de 70 . Entre outros fatores, as dificuldades de acesso, localização remota e a grande cobertura de floresta tropical, fizeram com que a geologia do Estado permaneça até hoje muito pouco conhecida. Uma revisão completa da geologia e estratigrafía da região é apresentada por Lima et al. (1974), Amaral (1984) e Lima et al. (1991) e não será abordada no presente trabalho. Contudo, alguns aspectos específicos, os quais são particularmente significativos para este trabalho, serão abordados a seguir. Estes incluem o embasamento cristalino, o Grupo Vila Nova e as associações de rochas máfico-ultramáficas intrusivas (Fig. 2).

Embasamento cristalino $\mathrm{O}$ embasamento da região é composto por terrenos de alto grau e magmáticas associadas, representados por gnaisse, migmatito, granito, tonalito e granulito ácido e básico, denominados de Complexo Guianense (Lima et al 1974). Montai vão \& Tassinari (1984) apresentam uma isócrona $\mathrm{Rb}-\mathrm{Sr}$ de referência de 2.944 Ma para tonalitos e gnaisses do Complexo Guianense. Os terrenos granito-gnaisse são polideformados e têm composição variável, predominando biotita-gnaisse, homblenda-gnaisse e tonalito. Entre os granulitos, predominam piriclasitos, com granulitos charnoquíticos egranoblastitos ocorrendo associados, apresentando marcante

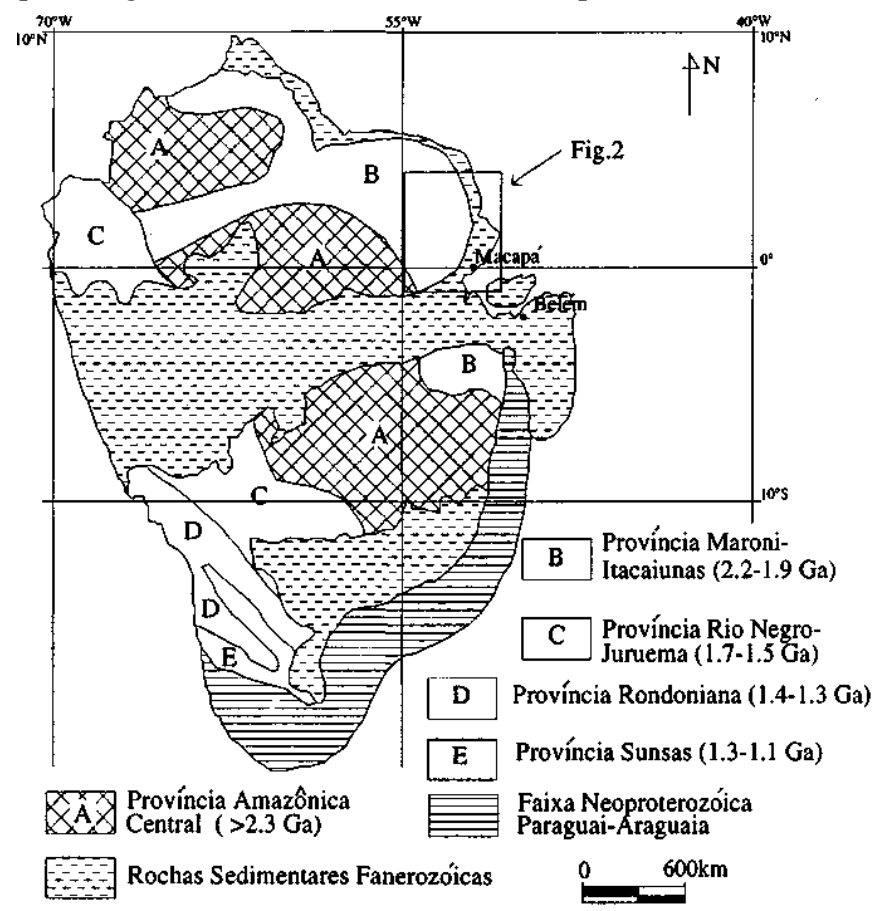

Figura l-Principais estruturas e feições tectônicas do Cráton Amazônico. Modificado de Tassinari (1997).

MBR, Av. de Ligação, 3580, Novo Lima - MG, CEP 34.000-000, e-mail cbs@mbr.com.br

UnB, Instituto de Geociências, Universidade de Brasília, Brasília-DF, CEP 70910-900, e-mail cesarf@unb.br 


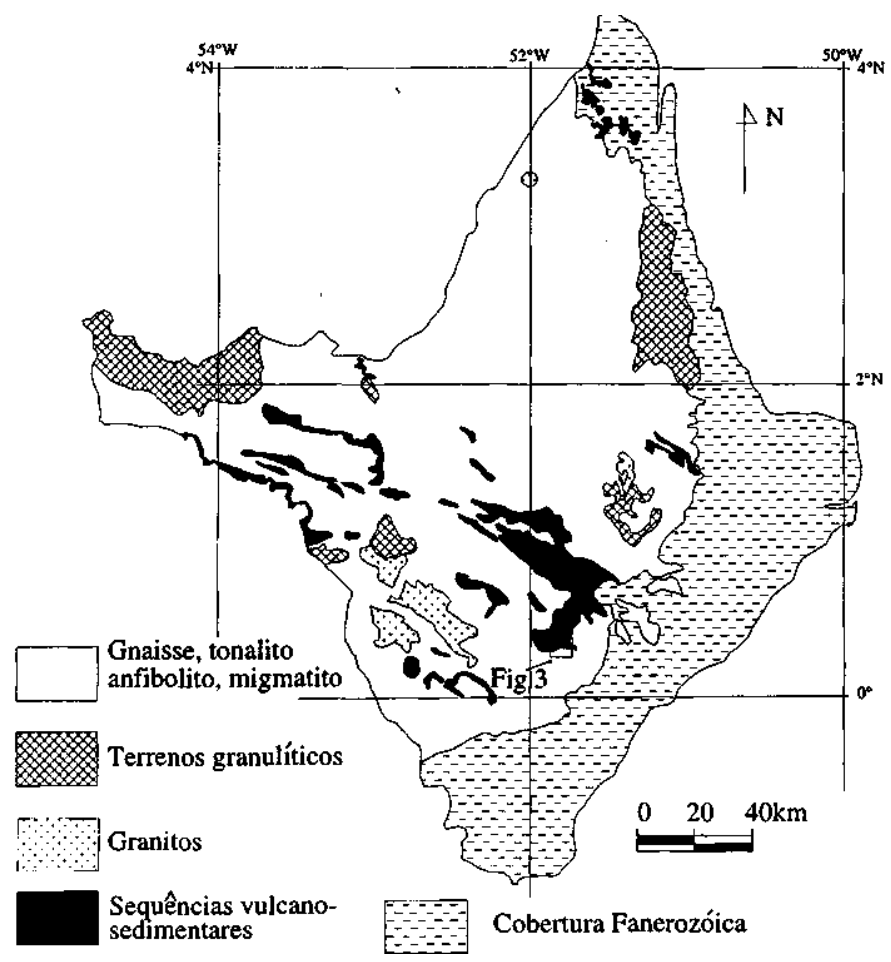

Figura 2 - Mapa geológico simplificado do Estado do Amapá. Modificado de Rodrigues et al (1988).

isotropia estrutural. Lima et al. (1982) obtiveram isócrona $\mathrm{Rb}-\mathrm{Sr}$ de $2.450 \pm 74$ Ma para os granulitos.

Grupo Vila Nova O Grupo Vila Nova (Lima et al. 1974) é uma sequência vulcano-sedimentar metamorfísada na fácies xisto verde a anfibolito, amplamente distribuída no Amapá e prolongando-se para a Guiana Francesa, onde apresenta continuidade física com os Grupos Paramacá e Marawijne (Costa \& Hasui 1997). Jorge João et al. (1979) consideram esta unidade como sendo um cinturão do tipo greenstone belt. Variedades de quartzito, metaconglomerado, xisto, mármore manganesífero, formação ferrífera bandada e anfibolito são as suas principais associações litológicas.

Na região da Serra do Navio, local onde o Grupo Vila Nova encontra-se melhor estudado, ocorre uma sequência basal de ortoanfibolito capeado por xisto e mármore manganesífero (Coelho Filho 1998). A oxidação dos carbonatos produziu os depósitos de manganês lavrados pela ICOOMI desde 1957 até sua exaustão em 1997. No total foram extraídas 61 milhões de toneladas de minério de Mn (Coelho Filho 1998). Datações K-Ar em micas provenientes de xisto (1.919 Ma el $.759 \mathrm{Ma}$ ) e anfibólios oriundos de anfibolito (2.088 Ma e $1.971 \mathrm{Ma}$ ) são os únicos dados geocronológicos disponíveis para o Grupo Vila Nova na Serra do Navio (Montalvão \& Tassinari 1984). As datações K-Ar indicam uma idade mínima para o evento metamórfico. A idade modelo Sm-Nd de $2.264 \pm 34$ Ma em anfibolitos do Grupo Vila Nova na Serra do Ipitinga é interpretada como a idade do vulcanismo (MacReath \& Faraco 1997).

Rochas máfico-ultramáficas intrusivas Rochas máfico-ultramáficas intrusivas foram inicialmente descritas na região do rio Preto (igarapé do Breu) por Coelho Filho et al. (1981). Os autores relatam a ocorrência de depósitos de cromita associados a rochas máfico-ultramáficas intemperizadas, considerados a época como depósitos do tipo alpino. Matos et al. (1992) descrevem os litotipos do Complexo Máfico-Ultramáfico Bacuri (CMUB), na região do rio Vila Nova, caracterizando pela primeira vez a presença de grandes complexos acamados hospedeiros de mineralizações de cromita no Amapá. Estudos específicos voltados para a distribuicão de Pt e Pd no minério de cromo do CMUB foram desenvolvidos por Sá et al. (1996a, 1996b). Os resultados indicam enriquecimento em Pt e Pd em algumas partes do complexo mas não apresentam os controles específicos desta concentração.

GEOLOGIA DA ÁREA DO PROJETO VILA NOVA O mapa geológico da área do Projeto Vila Nova (Fig. 3) é proveniente de

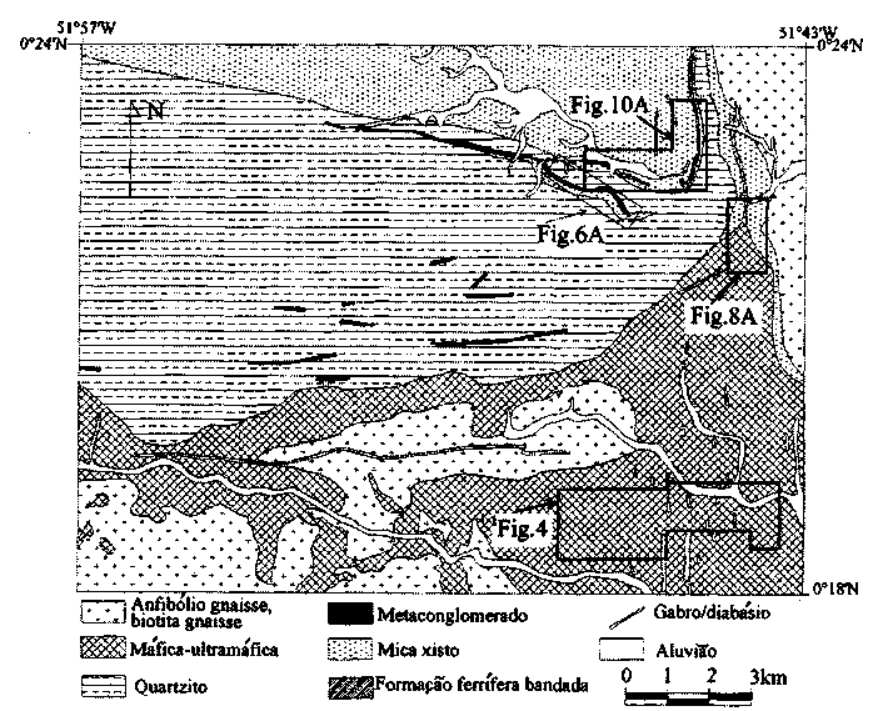

Figura 3 - Mapa geológico do Projeto Vila Nova. Modificado de Coelho Filho et al. (1987).

mapeamentos geológicos e levantamentos geoquímicos/geofísicos de detalhe realizados pela ICOMI/CFA no período de 1983 a 1996. Os seguintes conjuntos de rochas são identificados na área: (a) terrenos gnáissico-migmatíticos; (b) o Complexo Máfico-Ultramáfico Bacuri; (c) associação metas sedimentar com meta vulcânicas subordinadas; (d) granitóides e pegmatito (e) stocks de gabro e diques de diabásio.

Terrenos gnáissico-migmatíticos Os terrenos gnáissicomigmatíticos predominam na parte sul da área do Projeto VNO, tendo sido interceptados em alguns furos de sonda que atravessam o CMUB. Predominam gnaisses quartzo-feldspáticos e hornblenda gnaisses fortemente bandados. As rochas são polideformadas com remobilização e migmatização frequente. $\mathrm{O}$ gnaisse quartzo-feldpático é cinza claro, fino a médio e tem foliação penetrativa. Apresenta textura granoblástica a nematoblástica, sendo constituído essencialmente por plagioclásio e quartzo, com biotita, moscovita e feldspato potássico subordinados. $\mathrm{O}$ homblenda gnaisse tem cor cinza esverdeada e granulação média, com foliação bem desenvolvida. Apresenta textura granoblástica a nematoblástica, sendo formado por plagioclásio, quartzo e hornblenda, com biotita acessória. A paragêneses mineral Qtz + PI + Kfs + Ms (abreviações segundo Kretz 1983) é típica da fácies anfibolito, com ausência de paragêneses diagnosticas da fácies granulito. Os terrenos gnáissico-migmatíticos da area do Projeto VNO são preliminarmente correlacionados ao Complexo Guianense.

Complexo Máfico-Ultramáfico Bacuri As rochas do Complexo Máfico-Ultramáfico Bacuri ocorrem na porção central da área, estando parcialmente inseridas nos terrenos granito-gnáissicos. O CMUB é interpretado como um corpo intrusivo no Complexo Guianense. A natureza do contato está geralmente mascarada pela deformação e metamorfismo superposto. Além disto, as coberturas de solo e capeamento laterítico dificultam o mapeamento, o qual é parcialmente baseado na correlação com mapas de geoquímica de solo.

O CMUB tem direção aproximada EW, com $16 \mathrm{~km}$ de extensão e cerca de $1 \mathrm{~km}$ de largura, prolongando-se para fora da área do projeto em direção a sudoeste por mais pelo menos $15 \mathrm{~km}$. E formado por rochas máfico-ultramáficas metamorfísadas representadas principalmente por anfibolito, serpentinito, tremolitito e cromitito. O CMUB é fortemente deformado, apresentando estruturas complexas devido a redobramentos e falhamentos, sendo comum o posicionamento subvertical das camadas. Estruturas e texturas primárias estão eventualmente preservadas em zonas de baixa deformação (low strain zones), o que permite a identificação das rochas primárias. As paragêneses 
minerais das rochas máficas $(\mathrm{Cpx}+\mathrm{Hbl}+\mathrm{PI} \pm \mathrm{Bt} \pm \mathrm{Qtz})$ indicam metamorfismo em condições da fácies anfibolito superior. Um estudo detalhado da estratigrafia ígnea, petrografia e petrologia do CMUB está em desenvolvimento, e não será abordado neste trabalho.

A natureza estratiforme do CMUB é definida em função das características químicas e texturais dos cromititos e das rochas máficoultramáficas hospedeiras. Acamadamento magmático e texturas cúmulos são frequentes. As feições primárias estão melhor preservadas nos cromititos e serão consideradas junto com a descrição dos depósitos de cromita.

Associação metassedimentar com metavulcânicas subordinadas Rochas metassedimentares com metavulcânicas subordinadas, correlacionados ao Grupo Vila Nova, ocupam a porção norte da área, encobrindo parcialmente as rochas do CMUB. A associação metassedimentar é representada por sedimentos elásticos grosseiros (metaconglomerado), elásticos com granulação média a fina (quartzito conglomerático, quartzito e quartzo xisto), sedimentos de origem clasto-química (quartzito e xisto ferruginoso) e sedimentos químicos (itabirito, especularita xisto e metachert). Embora existam gradações e interdigitações frequentes entre os diversos litotipos, os sedimentos elásticos grosseiros predominam na base da sequência e gradam para sedimentos elásticos finos e sedimentos químicos em direção ao topo. As rochas metavulcânicas estão associadas aos sedimentos elásticos finos e aos sedimentos químicos.

Os metaconglomerados ocorrem na forma de lentes em quartzitos, muitas vezes apresentando gradacão granulométrica para os mesmos. São identificados dois tipos distintos de metaconglomerado. O primeiro, denominado de metaconglomerado basal, assenta-se em discordância erosiva sobre uma camada de quartzito xistoso microconglomerático. E uma rocha imatura, mal selecionada, constituída por seixos de quartzo e quartzito com diâmetro médio de $15 \mathrm{~cm}$, por vezes atingindo até $60 \mathrm{~cm}$. Seixos de mica xisto e rochas máfico-ultramáficas são frequentes na base do mesmo. A matriz constitui 50 a $65 \%$ do volume da rocha e é formada por quartzo, feldspato e sericita. Os acessórios mais comuns são turmalina e fucksita com cromita esporádica.

O segundo tipo de metaconglomerado ocorre intercalado a uma sequência de quartzito de granulação média a grossa, sobreposto ao metaconglomerado basal. Apresenta arcabouço formado dominantemente por seixos de quartzo e quartzito bem selecionados, com diâmetro médio de $10 \mathrm{~cm}$ e matriz constituída por quartzo, feldspato e sericita.

O quartzito ocupa grande parte da área mapeada, sendo formado principalmente por quartzo, feldspato e sericita. Predomina quartzito de granulação média a fina, com intercalações de lentes de mica xisto, quartzito conglomerático e metaconglomerado. Próximo ao contato com as rochas ultramáficas do CMUB, o quartzito tem coloração verde, passando a fucksita quartzito. Estratificação cruzada é observada em alguns cortes de galerias de pesquisa.

Mica xisto ocorre como camadas delgadas intercaladas no quartzito e como uma espessa sequência a norte da formação ferrífera. Apresenta granulação fina a muito fina e xistosidade bem definida, por vezes exibindo microdobras. A textura é granoblástica a lepidoblástica, com faixas de cor verde escura formadas por biotita e opacos intercaladas por faixas claras constituídas de quartzo e biotita ou somente quartzo, englobando porfiroclastos de quartzo ou porfiroblastos de granada. Seus principais constituintes mineralógicos são biotita (parcialmente alterada para clorita) e quartzo. Plagioclásio, granada, ilmenita e pirita ocorrem como acessórios e apatita como traços.

Rochas metassedimentares químicas, representados por formação ferrífera e chert estão presentes na região norte da área. A formação ferrífera é formada por itabirito e especularita xisto, que formam cristas alongadas e definem uma macroestrutura sinformal (Fig. 10 A-B). A geologia dos depósitos de minério de ferro é descrita no capítulo dos depósitos minerais do Projeto VNO. Lentes de metachert ocorrem intercaladas nas rochas metavulcânicas.

Rochas metavulcânicas básicas, representadas por anfibolito e anfibólio xisto ocorrem intercaladas no mica xisto e quartzito. Apresentam granulação fina, cor verde escura, foliação proeminente e eventuais porfiroblastos róseos de granada com diâmetros variando de 5 a $8 \mathrm{~mm}$. $\mathrm{O}$ anfibolito apresenta textura nematoblástica, sendo constituído essencialmente por hornblenda e subordinadamente por plagioclásio, quartzo e biotita. Titano-magnetita, calcopirita, pirita e titanita ocorrem como traços; $\mathrm{O}$ anfibólio xisto apresenta faixas de textura nematoblástica intercaladas por faixas granoblásticas. Nas primeiras predomina diopsídio com rara hornblenda, enquanto as segundas são formadas dominantemente por diopsídio mais grosseiro.
Os litotipos integrantes desta associação vulcano-sedimentar estão intensamente deformados, conforme indicado pelo forte estiramento dos seixos dos metaconglomerados e por dobramentos isoclinais no quartzito xistoso e no xisto. O metamorfismo de fácies anfibolito é definido pela paragêneses $\mathrm{Cpx}+\mathrm{Hbl}+\mathrm{PI}$ observada nas metavulcânicas básicas.

Granitóides e pegmatito Rochas graníticas metamorfisadas e corpos de pegmatito cortam todas as litologias anteriormente descritas. Os pegmatitos apresentam-se na forma de veios e pequenos corpos semicirculares, com dimensões variando desde centímetros a até algumas centenas de metros. Compõem-se de feldspato potássico e quartzo, frequentemente intercrescidos, com biotita, moscovita e granada acessórias. Alguns destes corpos são mineralizados, sendo conhecido no limite oeste da área um grande corpo de pegmatito, mineralizado a tantalita, trabalhado por vários anos por garimpeiros.

Stocks de gabro e diques de diabásio Stocks de gabro com dimensões variando desde 100 a até 1000 metros são comuns em vários pontos da área trabalhada. $\mathrm{O}$ gabro apresenta textura fanerítica equi. granular sendo PI e Cpx os principais constituintes mineralógicos. E comum a presença de texturas porfiríticas, com cristais de plagioclásio e mais raramente de piroxênio de até $6 \mathrm{~cm}$.

Diques de diabásio com textura afanítica e por vezes porfirítica distribuem-se por toda a área, frequentemente cortando os gabros descritos acima. Estas rochas são correlacionadas ao Diabásio Cassiporé de Lima et al. (1974).

OS DEPÓSITOS MINERAIS DO PROJETO VILA NOVA Histórico dos trabalhos de prospecção mineral Os trabalhos de prospecção mineral na área tiveram início em 1972, quando foram realizados levantamentos geológicos e geoquímicos, em escala regional, que permitiram identificar anomalias geoquímicas para cromo na área do Projeto VNO. Em 1983, foram iniciados os trabalhos de semi-detalhe, envolvendo novamente mapeamento geológico e geoquímico, quando além de diversas anomalias para cromo, foram também identificadas anomalias para ouro, que vieram a ser objeto de detalhamento.

Os alvos para pesquisa de cromo foram selecionados em função dos teores deste elemento encontrados na geoquímica de solo. Foram priorizados aqueles situados no lado sudeste da área, onde foram detectadas anomalias de até $17.000 \mathrm{ppm}$ de cromo, por vezes associadas a blocos de cromitito laterizado. Nestes alvos foram realizados levantamentos magnetométrico e gravimétrico, que aliados com as informações de geologia e geoquímica, permitiram priorizar as anomalias a serem sondadas. Foram realizados aproximadamente 70.000 metros de sondagem, que resultaram na descoberta de 11 corpos económicos de cromitito, com reservas de 9 milhões de toneladas, restando ainda várias ocorrências a serem trabalhadas. $\mathrm{O}$ início da lavra deu-se em 1989, tendo sido lavradas aproximadamente 2 milhões de toneladas de minério até 1997.

Os trabalhos de semi-detalhamento para ouro, envolvendo prospecção aluvionar e geoquímica de solo, mostraram que as maiores dispersões deste metal estavam localizadas nos solos provenientes da alteração de litotipos do Grupo Vila Nova. Por ocasião do detalhamento, foram amostrados os 5 metros iniciais do perfil de alteracão, em uma malha de 20 × 20 metros, que permitiu a seleção de dois alvos, denominados de Santa Maria e Vicente, onde foram realizados, respectivamente, 3.395 e 3.500 metros de sondagem, resultando na descoberta de dois depósitos de ouro com reservas preliminares de $1.100 \mathrm{~kg}$ (Depósito Santa Maria) e $2.500 \mathrm{~kg}$ (Mina do Vicente) (Fernandes et al. 1987,1989).

Geologia dos depósitos de cromita Os corpos de cromitito apresentam-se descontínuos (Fig. 4), concentrados no lado sudeste do CMUB, com dimensões dos depósitos variando entre 80 e 700 metros de extensão. Encontram-se associados à unidade ultramáfica, que apresenta espessura da ordem de $80 \mathrm{~m}$.

A camada principal de cromitito situa-se na interface entre rochas máficas e ultramáficas, apresentando espessura média de 12 metros. Camadas menores de cromitito, com espessuras variáveis desde alguns centímetros a até 3 metros ocorrem associadas às rochas ultramáficas.

Os corpos de cromitito apresentam geometria complexa decorrente da intensa deformação dúctil a que foram submetidos, exibindo formas variadas desde camadas e lentes até elipses (Fig. 5A). Corpos individuais da camada principal de cromitito apresentam continuidade lateral de até $100 \mathrm{~m}$ e espessuras variando entre 1 e $25 \mathrm{~m}$, com espessura média de 12 metros. E notável a grande continuidade vertical observada, atingindo em alguns locais a mais de $300 \mathrm{~m}$ (Fig. 5B). 
A camada principal é um cromitito maciço com mais de $70 \%$ de cristais de cromita, mostrando contato brusco com as encaixantes. Camadas menores de cromitito disseminado podem também ser observadas. Os grãos de cromita são euédricos, com granulometria uniforme e tamanho dos cristais variando de 0,1 a 0,6 mm, com tamanho médio de 0,2 mm. Raramente observam-se lâminas de cromita grosseira, com granulometria média de $1,5 \mathrm{~mm}$.

A alteração intempérica foi intensa, atingindo profundidades de até 120 metros nos locais topograficamente mais elevados. De acordo com sua posição em relação ao nível de intemperismo, o minério é classificado em laterítico, friável e compacto. $\mathrm{O}$ minério laterítico ocorre em regiões de platôs, onde afloram corpos de cromitito, estando restrito a profundidades de até $13 \mathrm{~m}$. Hidróxidos de ferro cimentam os grãos de cromita, formando rochas muito duras. O minério friável apresenta matriz constituída por argilo-minerais que passam, gradualmente, no minério compacto, a tremolita, clorita e esporadicamente ortopiroxênio e olivina. A Tabela 1 apresenta a composição química média dos minérios compacto e friável.

Geologia do depósito de ouro do Santa Maria Os depósitos auríferos do Santa Maria estão associados às rochas metassedimen-tares do Grupo Vila Nova, representados na área por: a) mica xisto e quartzo xisto; b) quartzito xistoso microconglomerático a turmalina; c) metaconglomerado polimítico e oligomítico d) quartzito conglomerático com intercalações centimétricas a métricas de metaconglomerado. As rochas metassedimentares formam uma macroestrutura homoclinal, com direção geral $\mathrm{N} 35^{\circ}-45^{\circ} \mathrm{W}$ e mergulho de $65^{\circ}$ a $85^{\circ} \mathrm{SW}$ (Fig. 3, 6 A-B).

Mica xisto e quartzo xisto formam a base da sequência elástica mais grosseira, sendo constituídos por quartzo, feldspato e sericita, com turmalina e fucksita acessórios. Sobreposto aos mesmos, ocorre o quartzito xistoso microconglomerático, que apresenta bandas milimétricas a centimétricas de turmalinito associado a veios de quartzo boudinados. Estes veios são concordantes com a foliação e têm espessuras entre 10 e $20 \mathrm{~cm}$. Este horizonte apresenta espessura variando de 5 a $15 \mathrm{~m}$ e, dada a sua grande continuidade lateral e vertical, foi utilizado como guia na prospecção.

Assentado sobre o horizonte guia, em discordância erosiva, ocorre uma camada de 8 a 13 metros de espessura de metaconglomerado imaturo, denominado de metaconglomerado basal. Esta rocha apresenta um arcabouço formado predominantemente por seixos de quartzo e quartzito mal selecionados, com diâmetro de até $60 \mathrm{~cm}$. Próximo à base deste metaconglomerado são frequentes seixos de mica xisto, turmalina quartzito e rochas máfico-ultramáficas. A matriz varia de 50 a $60 \%$ do volume da rocha e é formada por quartzo, feldspato, sericita, turmalina e fucksita, tendo sido verificada a presença de cromita em algumas amostras.

Acima do metaconglomerado basal ocorre uma sequência de quartzito de granulação média a grossa, conglomerático, constituído dominantemente por quartzo, feldspato e sericita, com intercalações de lentes centimétricas a métricas de metaconglomerado bem selecionado. Este quartzito grada para um espesso pacote de mica xisto, com formação ferrífera e metavulcânicas associadas.

Conforme observa-se na Fig. 7, o ouro está mais concentrado na base da sequência elástica grosseira, junto ao horizonte guia e ao metaconglomerado basal, assim como no contato do primeiro com os xistos. O ouro contido na camada guia está associado a bandas turmaliníferas e a veios de quartzo, apresentando maiores teores de prata quando comparado com os teores verificados no metaconglomerado basal. Por outro lado, os metaconglomerados superiores e quartzitos conglomeráticos apresentaram ampla disseminação de ouro, sugerindo uma origem sedimentar primária. Foi calculada uma reserva preliminar de 1,3 Mt de minério com teor médio de 0,84 g/t de Au (Fernades et al 1987).

Geologia da Mina de Ouro do Vicente A mina de ouro do Vicente está associada às rochas metassedimentares e metavulcânicas do Grupo Vila Nova. Na área da mina (Fig. 8 A-B) foram individualizados três conjuntos litológicos: a) rochas metassedimentares representadas por moscovita quartzito, granada-biotita-quartzo xisto e metachert, b) metavulcânicas básicas com tremolitito e serpentinito associados e c) veios de quartzo sulfetados mineralizados a ouro. Lentes de metachert ocorrem intercaladas nas metavulcânicas básicas. O tremolitito e o serpentinito são idênticos às rochas do CMUB, o que sugere que seu posicionamento intercalado nas rochas metassedimentares e metavulcânicas é de natureza tectônica. Todas estas unidades encontram-se profundamente intemperizadas a até uma profundidade média de $80 \mathrm{~m}$.

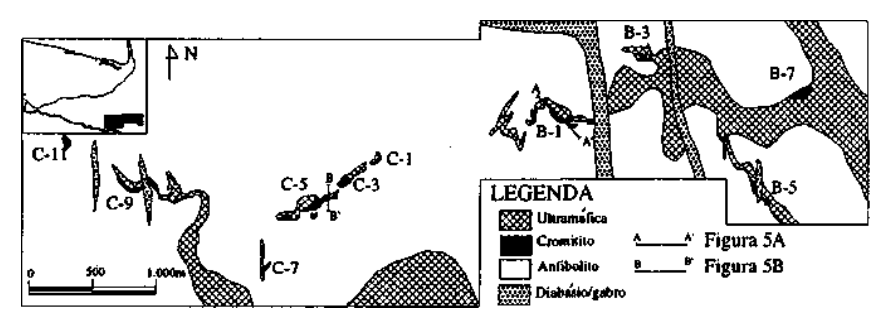

Figura 4 - Mapa geológico de detalhe da porção sul do CMUB destacando a localização das principais minas/depósitos de cromitito.

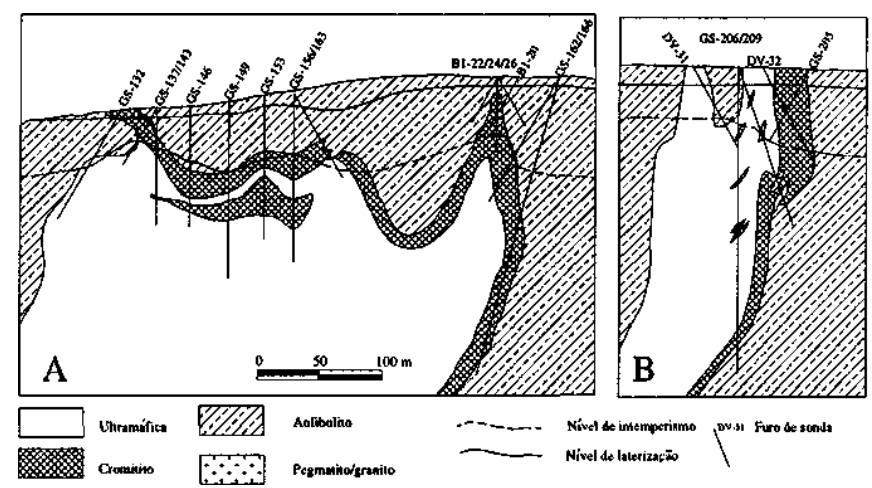

Figura 5 - Seções geológicas dos corpos de cromitito. A) Seção T-23 do corpo B-l. B) Seção 1280 do corpo C-5.

Os veios de quartzo têm orientação $\mathrm{N} 10^{\circ} \mathrm{W} / 40-70^{\circ} \mathrm{SW}$ concordante com a estrutura regional, estendendo-se por mais de $10 \mathrm{~km}$ ao longo dos quais ocorrem vários garimpes de ouro. Em escala de afloramento, os veios cortam as rochas metassedimentares e metavulcânicas, indicando a sua origem por remobilização.

Os veios de quartzo aurífero apresentam uma associação com sulfetos (pirita, calcopirita, pirrotita, arsenopirita e covelita). O ouro ocorre nas fraturas e, por vezes, em pequenos cristais inclusos em quartzo, pirita e arsenopirita. A figura 9 mostra a distribuição do ouro ao longo do furo GV-16.

Nos anos de 1.989 a 1.995 a parte norte do depósito, situada na margem esquerda do rio Vila Nova, foi invadida por centenas de garimpeiros, que trabalharam o minério oxidado, sendo desconhecido o total de ouro extraído. Na parte sul do corpo foi estimada uma reserva inicial de 2,0 Mt de minério com teor médio de 1,23 g/t de ouro (Fernandes et al 1989). A partir de 1.994 foi iniciada a lavra na área Sul e em 1 .996, com a saída dos garimpeiros, também da área norte, tendo sido extraídas até dezembro de 1.997 aproximadamente $2.600 \mathrm{~kg}$ de ouro.

Geologia dos depósitos de ferro Os depósitos de minério de ferro do Projeto VNO são conhecidos desde 1947, quando a Hanna Exploration Co executou uma campanha de sondagem rotativa, visando quantificar e qualificar as ocorrências de ferro da região. Nesta ocasião foram realizados $1.716 \mathrm{~m}$ de sondagem, que permitiram a definição de 4 jazidas, denominadas de Bacabal, Leão, Santa Maria e Baixio Grande.

Os depósitos têm forma de camadas descontínuas de hematita compacta e especularita, intensamente falhados, com comprimentos variando de $250 \mathrm{~m}$ a $1000 \mathrm{~m}$ e espessura média de $20 \mathrm{~m}$, que acompanham a estrutura regional (Fig. $10 \mathrm{~A}$ ), formando grandes afloramentos que se destacam na topografia. As encaixantes do minério são itabirito, sericita xisto e quartzito do Grupo Vila Nova que, a exemplo dos demais depósitos, apresentam-se intensamente intemperizados.

$\mathrm{Na}$ Jazida Bacabal, a camada de hematita apresenta-se na forma de um sinforme, com eixo $\mathrm{N} 10^{\circ} \mathrm{W}$ e caimento de $80^{\circ} \mathrm{NW}$ (Fig. 10B). A tabela 2 apresenta a tonelagem e teores de cada depósito.

Trabalhos posteriores de mapeamento regional, realizados pela ICOMI na década de 90, detectaram a continuidade da formação ferrífera para nordeste da área. Entretanto, devido a baixa tonelagem dos depósitos, é difícil tornar viável a sua exploração económica.

DISCUSSÃO Diversos autores (Gibbs \& Olszewski 1982, Gibbs \& Barron 1983, Gruau et al. 1985) têm apresentado dados geocronológicos indicando que os greenstone belts do Escudo das Guianas são paleoproterozóicos, com idades entre 2. 1 e $2.3 \mathrm{Ga}$. Gibbs \& Barron 
Tabela l - Composição química do minério de cromo do CMUB Modificado de Matos et al. (1992).

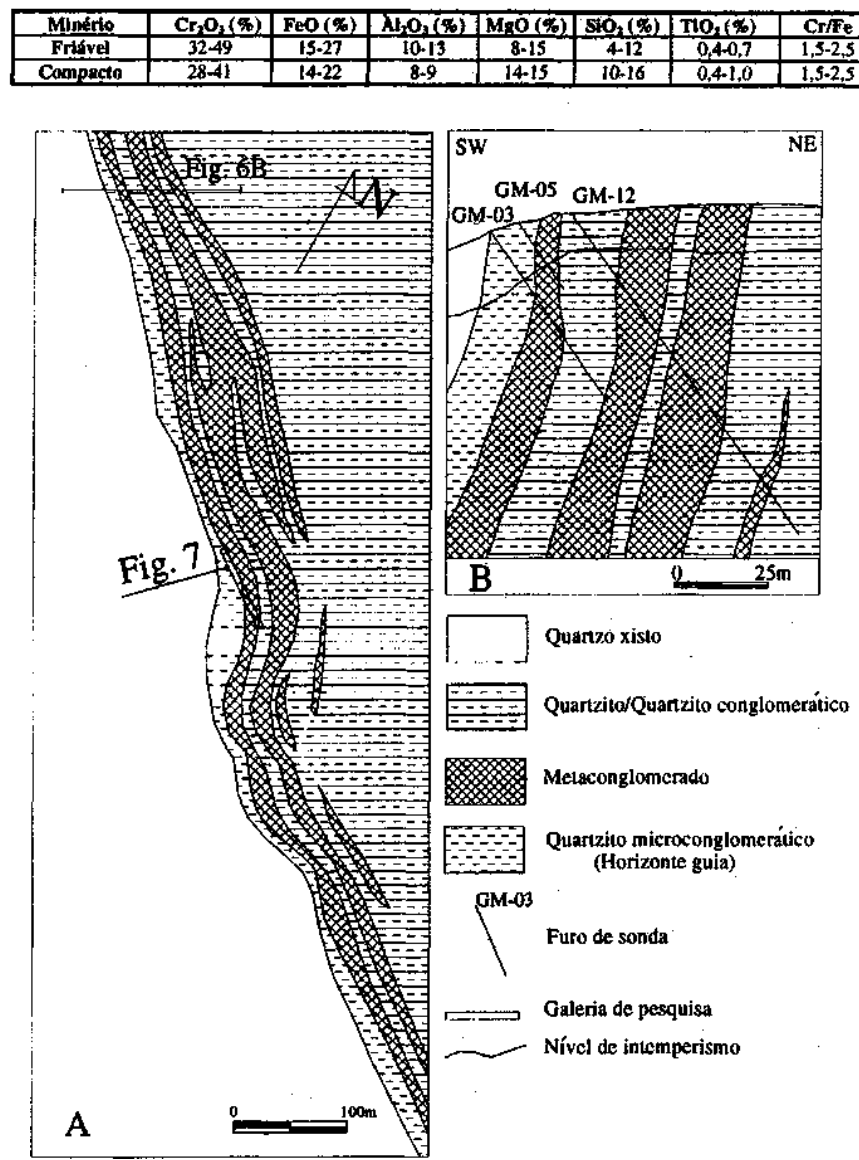

Figura 6 - A) Mapa geológico esquemático do depósito do Santa Maria. B) Seção geológica 150 do depósito do Santa Maria. Modificado de Fernandes et al. (1987).

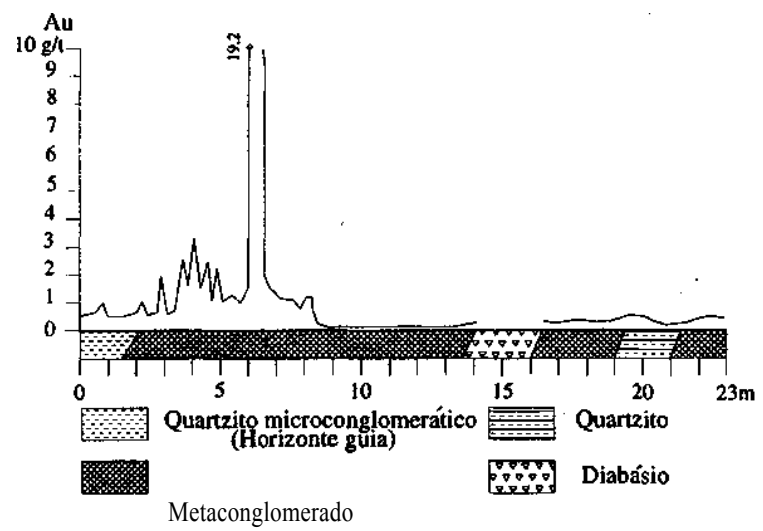

Figura 7 - Distribuição do Au na galeria principal de pesquisa do depósito do Santa Maria. Modificado de Fernandes et al. (1987).

(1983) destacam as similaridades litológicas, estruturais e metamórficas entre vários greenstone belts do Escudo das Guianas, observando que em contraste com os típicos greenstone belts Arqueanos eles apresentam menor proporção de rochas máficas e ultramáficas. $\mathrm{O}$ Grupo Vila Nova é considerado como cronologicamente equivalente aos greenstone belts do norte do Escudo das Guianas, o que foi recentemente comprovado pela datação Sm-Nd de 2.264 $\pm 34 \mathrm{Ma}$ em anfibolitos da Serra do Ipitinga (MacReath \& Faraco 1997). Diferenças marcantes entre o Grupo Vila Nova e os greenstone belts guianenses incluem o grau metamórfico geralmente mais elevado e a ausência de um vulcanismo ácido expressivo no primeiro. As rochas vulcano-sedimentares mapeadas na área do Projeto VNO reforçam estas duas diferenças. $\mathrm{O}$ metamorfismo indicado pela paragêneses $\mathrm{Cpx}+\mathrm{Hbl}+$ $\mathrm{P} 1$ das rochas máficas é típico da fácies anfibolito superior. Vulcânicas
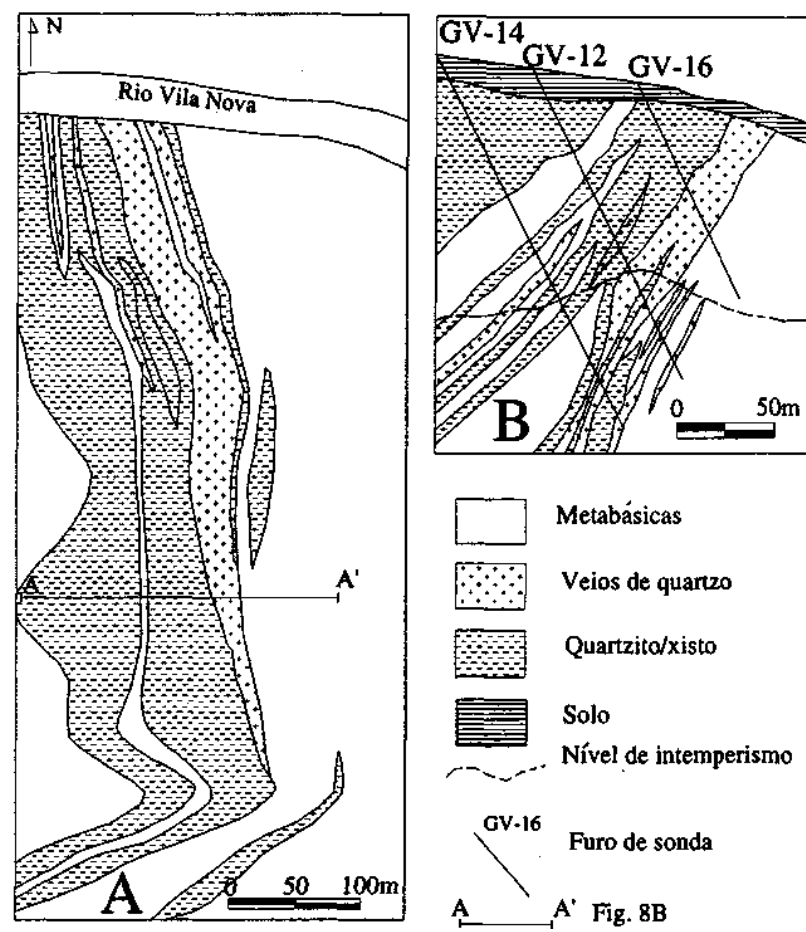

Figura 8 - A) Mapa geológico esquemático da parte sul da Mina do Vicente. Modificado de Fernandes et al. (1989). B) Seção geológica 11.650 N da Mina do Vicente. Modificado de Fernandes et al (1989).

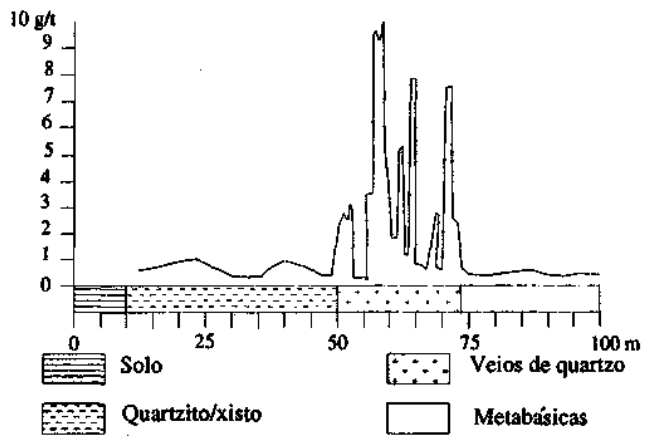

Figura 9 - Distribuição do Au no Furo GV-16 representado na figura 8. Modificado de Fernandes et al (1989).

Tabela 2 - Reserva geológica e teores das jazidas de ferro do Projeto Vila Nova (Fernandes et al. 1987).

\begin{tabular}{|c|c|c|c|c|c|}
\hline JAZIDA & BACABAL & LEAO & $\begin{array}{l}\text { SANTA } \\
\text { MARIA }\end{array}$ & $\begin{array}{l}\text { BAIXIO } \\
\text { GRANDE }\end{array}$ & TOTAL \\
\hline Rescrya (M) & 6.848 & 1.808 & 328 & 2.843 & 12.028 \\
\hline $\operatorname{Fe}(\$)$ & 62,42 & 58.12 & 35,03 & 62,00 & 61.35 \\
\hline$\overline{P(\infty)}$ & 0,06 & 0,14 & 0,07 & 0,04 & 0,07 \\
\hline $\mathrm{SiO}_{2}(\bar{w})$ & 5,37 & 4,14 & 7,22 & 4,26 & 5,00 \\
\hline
\end{tabular}

ultramáficas e félsicas não foram identificadas na área do projeto, o mesmo ocorrendo nas regiões das serras do Navio (Coelho Filho 1998) e Ipitinga (MacReath \& Faraco 1997). Comparando-se a coluna estratigráfica da região de Serra do Navio com aquela da área do projeto VNO (Fig. 11), verifica-se na primeira a ausência dos sedimentos elásticos grosseiros na base enquanto que na segunda está ausente a metavulcânica básica. Estes fatos sugerem uma maior proximidade da área do Projeto VNO do limite da bacia sedimentar. Fernandes et al. (1987) observam que o aporte de sedimentos às bacias originárias do Grupo Vila Nova na área do Projeto VNO deu-se inicialmente de forma rítmica, sendo a sedimentação de borda retrabalhada, propiciando a formação de lentes de conglomerados. Os autores descrevem a presença de feições faciológicas marcantes, indicativas de paleoambientes proximais, na forma de leques aluviais e cabeceiras de paleodrenagens. Estes dados contrastam com o ambiente de mar aberto descrito para a região da Serra do Ipitinga (MacReath \& Faraco 1997) e de bacia marginal sugerido por Coelho Filho (1998) para Serra do Navio. 


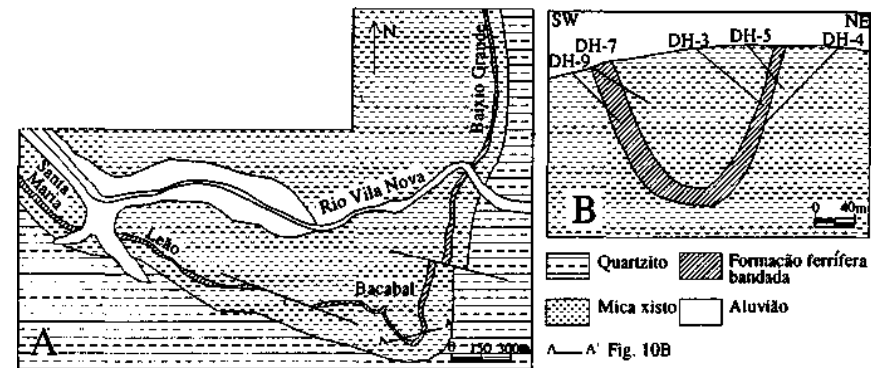

Figure 10 - A) Mapa geológico esquemático mostrando a localização das jazidas de ferro. Modificado de Fernandes et al. (1987). B) Perfil geológico da Jazida Bacabal. Modificado de Fernandes et al. (1989).

A presença de seixos de rochas máfico-ultramáficas e de grãos de cromita no metaconglomerado basal sugere que o CMUB é mais antigo do que o Grupo Vila Nova, indicando a existência de importante magmatismo mantélico anterior ao mesmo. Estudos petrológicos e geocronológicos estão sendo desenvolvidos para a caracterização petrotectônica destes corpos acamadados, os quais representam um importante potencial metalogenético para a região.

A existência de magmatismo komatítico na base do Grupo Vila Nova é apresentada por diversos autores (Luz et al. 1985, Montalvão 1985, Lima et al. 1991). As rochas máfico-ultramáficas descritas por Montalvão (1985) na área do Projeto Cupixi como komatíticas e integrantes do Grupo Vila Nova são petrograficamente similares às rochas ultramáficas metamorfisadas do CMUB. Além disto, o autor não apresenta dados estruturais e texturais que permitam a caracterização das rochas ultramáficas do Projeto Cupixi como vulcânicas. Na ausência de critérios estruturais-texturais, a utilização de dados petroquímicos é questionável e certamente não conclusiva. A relativa proximidade do Projeto Cupixi com o Projeto VNO, aliado à grande extensão regional das associacões máfico-ultramáficas intrusivas mineralizadas à cromita determinada pelos trabalhos de exploração regional desenvolvidos pela ICOMI/CFA, nos leva a questionar a existência de um magmatismo komatíítico expressivo associado ao Grupo Vila Nova. Esta observação têm implicações importantes para a avaliação metalogenética do Grupo Vila Nova e do Estado do Amapá.

CONCLUSÃO Trabalhos sistemáticos de prospecção mineral, desenvolvidos desde meados da década de 80 , permitiram a descoberta de importantes depósitos minerais na área do Projeto VNO. Embora carecendo ainda de estudos metalogenéticos específicos, a diversidade dos depósitos indica a multiplicidade dos processos mineralizantes atuantes na região. Dentre estes destacam-se os depósitos de cromita,

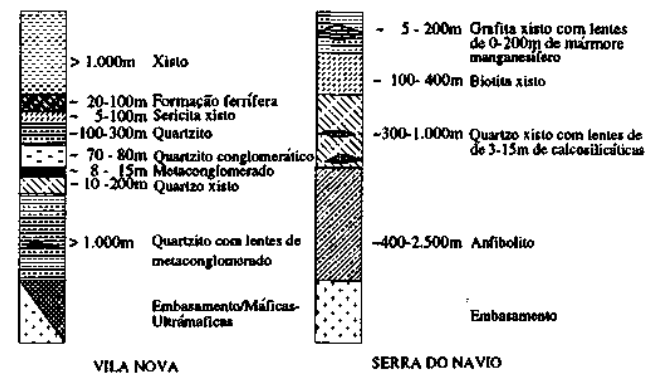

Figura 11. Coluna estratigráfica esquemática das regiões de Serra do Navio e Vila Nova. Modificado de Coelho Filho (1998) e de Coelho Filho et al. (1987).

com características geológico-texturais semelhantes a depósitos magmáticos estratiformes. $\mathrm{O}$ depósito de $\mathrm{Au}$ do Santa Maria destaca-se pela associação com metaconglomerados e quartzitos em um contexto geológico semelhante a depósitos do tipo Rand. O depósito de Au do Vicente está associado a veios de quartzo e sulfeto em estruturas de cisalhamento dúctil sugestivas de uma mineralização do tipo quartz lode. Os depósitos de ferro são caracterizados pela grande continuidade lateral da formação ferrífera e indicam um processo sedimentar de mineralização. Os garimpes e/ou ocorrências de diamante e tantalita reforçam a diversidade de processos metalogenéticos atuantes na área do Projeto VNO. Considerando-se ainda a proximidade do Projeto VNO com os depósitos de manganês de Serra do Navio e com o depó-sito de ouro da Serra da Canga, além dos inúmeros garimpos de ouro, diamante e tantalita, verifica-se a concentração anómala de bens minerais nesta região, que pode tornar-se uma nova Província Mineral no Brasil.

Agradecimentos Este trabalho é uma parte da dissertação de mestrado do primeiro autor no Departamento de Geologia da Universidade de Brasília e representa o resultado de mais de 12 anos de experiência profissional como geólogo da ICOMI/CFA na área do Projeto VNO. Carlos Alberto Spier agradece ao Dr. Marcos Domingos da Costa, diretor da ICOMI, por tê-lo liberado para a realização do curso e por permitir a publicação dos dados. Ao Dr. Júlio César Nery da Silva, gerente de tecnologia e planejamento da MBR, por ter permitido a continuidade do curso após sua transferência para esta empresa. César F. Ferreira Filho agradece ao CNPq pela bolsa de pro-dutividade em pesquisa (Processo: 520457/96-0). Os autores agradecem o apoio oferecido pela ICOMI durante os trabalhos de campo.

\section{Referências}

Amaral, G. 1984. Províncias Tapajós c Rio Branco. In: F.F.M. Almeida; Y. Hasui (cds.) $O$ Pré-Cambriano do Brasil. São Paulo, Edgard Blucher, 6-35.

Coelho Filho, A.C. 1998. Exaustão das Reservas Remanescentes do Distrito Manganesífero de Serra do Navio. ICOMI (Relatório Interno)

Coelho Filho, A.C.; Kozuki, R.; Marques, S.P.P.; Costa, A.P. 1981. Relatório Final de Pesquisa de Cromita do Igarapé do Breu, Município de Mazagão-Amapá. Processo DNPM 807.701/75. Mineração Itaúba Lida. Belém (Relatório Interno DNPM).

Coelho Filho, A.C.; Spier, C.A; Matos, A.A. de; Soares, J.W.; Siqueira, E.M.; Lima, L.C.; Araújo, J.G. de. 1987. Relatório Final de Pesquisa de Cromita do Vila Nova, Município de Mazagao-Amapá. Processo DNPM 850.211/80. Mineração Itaúba Lida. Belém(Relatório Interno DNPM)

Costa, J.B.S.; Hasui, Y. 1997. O Pré-Cambriano da Região Amazônica no Brasil. In: SBG, Simpósio Nacional de Estudos Tectônicos, 6, Pirenópolis-GO, Anais, p. 39-41.

Fernandes, E.Z.; Pickerel, M.T.; Guedes, S.C. 1987. Projeto Vila Nova - Relatório Final de Pesquisa. Processo DNPM 850.048/80. Mineração Amapari Ltda. Belém, (Relatório Interno DNPM).

Fernandes, E.Z:; Pickerel, M.T.; Guedes, S.C. 1989. Projeto Vila Nova - Relatório de Reavaliação de Reservas. Processo DNPM 850.048/80. Mineração Amapari Ltda. Belém, (Relatório Interno DNPM)

Gibbs, A.K.; Barron, C.N. 1983. The Guiana Shield Rcviewed. Episodes, 1: 7-14.

Gibbs, A.K.; Olszewski Jr., W.J. 1982. Zircon U-Pb ages of Guyana grecnstone-gnciss terrane. Precambrian Research, 17: 199-214

Gruau, G.; Martin, H.; Leveque, B.; Capdevila, R.; Marot, A. 1985. Rb-Sr and Sm-Nd geochronology of lower Protcrozoic granile-greenstone terrains in French Guiana, South America. Precambrian Research, 30: 63-80.

Jorge João, X. da S.; Carvalho, J.M. de A.; Vale, A.G.; Frizzo, S.J.; Martins, R.C. 1979. Projeto Falsino -Relatório Final. Belém, DNPM-CPRM.

Kretz, R. 1983. Symbols for rock-forming minerais. American Mineralogist, 68: 277-279.

Lima, M.I.C. dç; Montalvão, R.M.G. de; Isslcr, R.S.; Oliveira, A.da S.; Basei, M.A.S.; Araújo, J.F.V.; Silva, G.G. da. 1974. Geologia. Folha NA/NB. 22 (Macapá). Levantamento de Recursos Naturais 6:1-120, Projeto RADAM, Departamento Nacional da Produção Mineral, Rio de Janeiro.
Lima, M.I.C. de; Oliveira, E.P. de; Tassinari, C.C.G. 1982. Cinturões Granulíticos da Porção Setentrional do Craton Amazônico. In: SBG, Symposium Amazonico, 1, Belém, Anais, 1: $147-162$.

Lima, M.I.C. de; Bezerra, P.E.L.; Araújo, C.C.G. 1991. Sistematização da Geologia do Estado do Amapá. In: SBG-Núcleo Norte, Simpósio de Geologia da Amazónia, 3, Belém, Anais , 322-335.

Luz, D.S. da; Moreira, M.L.O.; Prado, P. 1985. Evolução Geotectônica da Faixa Orogênica Tumucumaque-Vila Nova (Amapá). Projeto RADAM (Relatório Interno), Goiânia, 1 Ip.

Matos, A.A.; Spier, C.A.; Soares, J.W. 1992. Depósitos de Cromita da Região do Rio Vila Nova, Estado do Amapá. In: SBG, Congresso Brasileiro de Geologia, 37, São Paulo, Anais, 246-247.

McReath, L; Faraco, M.T.L. 1997. Sm-Nd and Rb-Sr systems in part of the Vila Nova mctamorphic suite, northern Brazil. In: SBG, South-American Symposium on Isotope Gcology, 1. Campos do Jordão, Extended Abstracts, p. 194-196.

Montalvão, R.M.G.; Tassinari, C.C.G. 1984. Geocronologia Pré-Cambriana do Território Federal do Amapá (Brasil). In: SBG, Symposium Amazonico, 2, Manaus, Anais, 53-57.

Montalvão, R.M.G. 1985. Pctrologia das Rochas Máfico-Ultramáficas do Supergrupo Vila Nova (Greenstonc Belt) e Grupo Roraima (Greenstone Bell) e Encraves na Região do Parima.

Rodrigues, E.M.; Benoliel, B.I.; Jorge João, X. da S. 1988. Mapa Geológico do Território Federal do Amapá. Escala 1:1.000.000. DNPM, Belém.

Sá, J.H.S.; Prichard, H.M.; Fisher, P.; Spier, C.A.; Matos, A.A. 1996a. Elementos do Grupo da Platina no minério de cromo do Complexo Bacuri, Estado do Amapá. In: O. J. Marini (cd.), Caracterização de Minérios e Rejeitos Minerais Brasileiros, DNPM, 55-60.

Sá, J.H.S.; Prichard, H.M.; Fisher, P.; Spier, C.A.; Matos, A.A. 1996b. Elementos e minerais do grupo da platina no Complexo máfico-ultramáfico Bacuri, Amapá. In: SBG, Congresso Brasileiro de Geologia, 39, Salvador, Anais, 5: 199-202.

Tassinari, C.C. 1997. The Amazonian Craton In: M. De Wit \& L. D. Ashwal (eds.), Greenstone Belts. Oxford Monographs on Geology and Gcophysics 35. Oxford Science Publications, Claredon Press, 558-566. In: SBG, Simpósio de Geologia da Amazónia, 2, Belém, Anais, 110-124 